\title{
Unhealthy Attitude or Behavior Factors and Habitual Sugar Sweetened Beverages Consumption in Junior School Students: a Cross-Sectional Study in 2020 and Long Term Trend From 2012 to 2020
}

\author{
Yuting Peng \\ Nanjing Medical University \\ Danyang Wang \\ Nanjing Medical University \\ Rui Zhang \\ Nanjing Medical University \\ Rujun Ai \\ Nanjing Medical University \\ Xiaofang Lin \\ Nanjing Medical University \\ Jieshu Wu ( $\boldsymbol{D}_{\text {jwu@njmu.edu.cn ) }}$ \\ Nanjing Medical University https://orcid.org/0000-0002-5600-7784
}

\section{Research}

Keywords: Sugar sweetened beverages (SSBs), Unhealthy attitude and behavior, Consumption frequency, Junior school student

Posted Date: October 28th, 2020

DOI: https://doi.org/10.21203/rs.3.rs-96854/v1

License: (c) (i) This work is licensed under a Creative Commons Attribution 4.0 International License. Read Full License 


\section{Abstract}

\section{Background}

Sugar-sweetened beverages (SSBs) consumption is the major source of added sugar intake and a common unhealthy eating behavior among youth in China and around the world. Excessive intake of SSBs has a negative impact on both short- and long-term health of adolescent. The targeting nutritional education and behavioral guidance, single use or as a supplement to the policy intervention like sales ban, is a low cost and effective intervening approach. The purpose of this study was to identify unhealthy attitudes and behaviors that affect youth's consumption of sugary drinks to provide evidence for subsequent targeted interventions.

Methods

Using the stratified cluster sampling method, a questionnaire survey was conducted among 1560 junior school students in Jinzhong City, Shanxi Province, in northern China and Suzhou City, Jiangsu Province, in southern China. The content of the questionnaire included sociodemographic characteristics, selfreported consumption frequency of SSBs, attitude, behaviors and habits related to SSBs consumption. The Cronbach coefficient of questions was 0.855. Data from the series surveys of 2012 and 2018 were also used in the long-term trend analysis.

Results

In 1466 Chinese junior school students, $5.1 \%$ consumed SSBs every day and $13.6 \%$ consumed it 3-6 times/week. The binary logistic regression was significant $\left(R^{2}=31.1 \%, P=0.001\right)$, and the attitude and behavior factors contributed to $22.1 \%$ of the $31.1 \%$ variation that could be explained. Among all factors, four unhealthy attitudes or behaviors with the highest OR were "Drink SSBs as water" (OR $=10.288,95 \% \mathrm{Cl}$ : 6.392 16.558), "Deem SSBs not affect health" (OR=2.735, 95\%Cl: 2.032 3.681), "Just want to drink SSBs" (OR=2.302, 95\%Cl: 1.524 3.478) and "Purchase SSBs in advance" (OR=2.245, 95\% Cl:

1.454 3.465). The SSBs consumption frequency increased with the increase of risk score of unhealthy attitudes and behaviors. $\left(X^{2}\right.$-trend $\left.=127.470, P<0.001\right)$. Both frequency of drinking SSBs and holding rates of unhealthy attitudes or behaviors decreased with the passage of time $\left(P_{\text {trend }}<0.005\right)$. The drinking times per month was significantly positively correlated with the risk scores from 2012 to $2020(r=0.314$, $P<0.001)$.

\section{Conclusion}

The consumption of sugary drinks was largely influenced by unhealthy attitudes and behaviors. Adolescents are in the critical period of cognitive and habit formation, thus targeted intervention should be taken to promote their SSBs related healthy attitude and behavior to reduce the intake of added sugar and benefit them for life. 


\section{Introduction}

Globally beverage production has increased dramatically, accompanied by rapid growth in consumption in recent decades. Taking China for example, the yield of beverages in 2017 (180 million tons) was 12 times that in 2010 (14.9 million tons) and increased 440 times over that in 1992; the average consumption of beverages in $2014(119 \mathrm{~kg})$ was nearly 10 times that in $2003(12 \mathrm{~kg})$ [1, 2]. More than half of both production and consumption were sugar-sweetened beverages (SSBs) in China [2].

As consumption of beverages has increased, so have the health risks associated with SSBs $[3,4]$. Singh estimated that a total of 184000 deaths and 8.5 million disability-adjusted life years were related to SSBs intake yearly worldwide in 2010 [5]. The follow up of 120,000 people about 30 years up to 2014 showed that those who consumed SSBs more than 2 cups per day had a $21 \%$ increased risk of death from all causes, among which a $31 \%$ increased risk of death from cardiovascular diseases and a 16\% increased risk of death from cancer, compared with those consuming less than 1 cup of sugar-sweetened beverages per month [6]. Consumption of sugary beverages has become an important risk factor for chronic diseases.

Based on the National Health and Nutrition Examination Survey (NHANES) data, about $50 \%$ of Americans in 2009-2010 [7], 50\% of adults and 60\% of youth in the U.S. in 2011-2014 consumed SSBs every day. SSBs were also the largest source of added sugars in the diet of adults [8] and youth aged 2 to 19 years [9] in the U.S. Notably, teenagers consumed more sugary drinks than adults in several countries $[10,11]$. In China, the total sugar consumption was low in the world compared with other developed countries, but too much intake of sugary drinks in children and adolescent was also a prominent problem, especially in the youth 12-17 $[12,13]$. Excessive consumption of SSBs increased the risk of dental caries in adolescents [14]. More importantly, a growing body of evidence supported the negative health effect of SSBs to chronic disease such as overweight and obese [15], metabolic syndrome, hypertension [16, 17] and dyslipidemia $[18,19]$ not only in adults but also in children and adolescents. Therefore, there is an urgent need to intervene in children's unhealthy eating habits of sugary drinks consumption.

Adolescence is a critical period for good habit formation, and the latter will have positive impact on lifelong health. In the intervention of SSBs consumption, nutrition education and behavior guidance are common and the most cost-effective methods, and policy interventions such as sales ban would also have better and more lasting effect if supplemented by targeted health education. However, researches had shown that not all knowledge was significantly associated with consumption of SSBs [20], and the change of nutrition information in label did not influence the choice of SSBs [21]. Only high behavioral relevant education or guidance may benefit to transfer into corresponding attitude and improve people's behavior $[22,23]$. The aim of this research is to identify the key risk attitudes and behaviors related to consumption of sugary drinks and provide a basis for subsequent targeted behavioral nutrition interventions.

\section{Subjects And Methods}




\section{Participants and procedures of survey 2020}

The aim of this study was to investigate the influence of unhealthy attitude and behavior towards beverage on habitual SSBs consumption in junior school students. We used stratified cluster sampling to recruit the participants. First, three middle schools were selected from Jinzhong city in Shanxi Province in northern China and Suzhou city in Jiangsu Province in southern China. Then 5-10 classes for each school were selected randomly, and all 1560 students in above classes were included in the survey. After giving informed consent to participate in this study, all students and their parents were asked to complete a questionnaire together between March and May 2020, including personal and family information, SSBs consumption attitudes, behaviors and habits etc. We encourage completing the habits and attitudes part by students themselves to obtain the fact of children and adolescents, not parents, while the personal and family information part was finished by their parents to ensure accuracy. Ethical approval was granted by the Ethics Committee of Nanjing Medical University in Nanjing, Jiangsu, China, 21/12/2017, No.392.

\section{Analytic samples of long term trend from 2012 to 2020}

In the long-term trend analysis, we also used the data from the SSBs consumption survey in 2012 and 2018 among primary and junior school students. The participants of 2012 survey was a small sample from Lianyungang City, Jiangsu Province, with a total of 189 junior school students. And 1670 junior school students in survey 2018 from the same schools with survey 2020 were selected. Due to the different gender composition of the samples selected in three surveys, the lowest number of respondents in 2012 was taken as the benchmark. After sampling by gender composition, 189, 1338 and 1,200 junior school students in 2012, 2018 and 2020 survey respectively were included in the final analysis of secular trend.

The flow chart of sample selection in this study was shown in Figure 1.

Figure 1. Flow chart for the inclusion of analytic participants in this study

\section{Questionnaire design and quality control}

Based on literature review, discussion of the project team, expert assessment and pilot studies, the questionnaire was formulated after multiple modification. The content of the questionnaire included sociodemographic characteristics, self-reported usual consumption frequency of SSBs, attitudes, behaviors, and habits related to SSBs consumption. Questions about SSBs consumption frequency

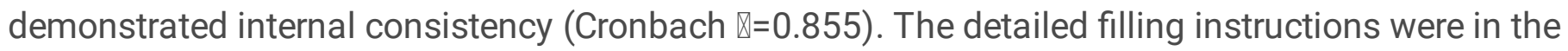
questionnaire, and the time for finishing questionnaire was controlled in 20 minutes to ensure good compliance. Some key questions were repeated asked in different forms at different time to check consistency. Specially-assigned persons are responsible for explaining the questionnaire and checking the submitted information. 
Respondents were asked to indicate their habitual SSBs consumption frequency by using 1 food frequency questionnaire-style screener question: (1) "How often do you usually drink sugar-sweetened beverages?" Students need to choose one of below five categories: $\geq 1$ times/day, 3-6times/week, 12times/week, 1-3times/month, <1 times/month. In binary logistic regression, we converted the consumption frequencies into two categories: $\geq 3$ times/month and $<3$ times/month to meet the requirements of model applicability. Above SSBs consumption frequency were converted in sequence to 30, 20, 6.5, 2 and 0.5 times/month in the secular trend analysis from 2012 to 2020.

\section{The obtainment of unhealthy attitude or behavior factors and combined risk scores}

The attitudes and behaviors toward SSBs were assessed by four questions. They were (1) "Do you drink SSBs just because you want to drink, not for hunger or thirst?" (Abbreviated as "Just want to drink SSBs" below) (Yes/no), (2) "Do you drink SSBs as water?" (Abbreviated as "Drink SSBs as water" below) (Yes/no), (3) "Do you think sugary drinks do not affect health?" (Abbreviated as "Deem SSBs not affect health" below) (Yes/no/not sure) and (4) "Will you buy SSBs in advance?" (Abbreviated as "Purchase SSBs in advance" below) (Yes/no). Then different answers to different questions were assigned different points, and the points of the first three questions were added up for a risk score. Question (4) was not calculated into risk score because it was not involved in the 2012 survey. For the question (1) and (2), answer "yes" were valued 1 point and answer "no" meant 0 point. While for the question (3), answer "no" was equal to 0 point, answer "not sure" was 1 point and answer "yes" was 2 points. The combined risk scores were divided into four categories: $0,1,2$, and $\geq 3$.

\section{Data analysis}

After checking, the data were analyzed by IBM SPSS Statistics Premium V25.0 and Stata/MP 15 software. The frequency of SSBs consumption was described by rate and rank sum test was used for the comparison of SSBs consumption frequency among people with different attitudes and behaviors. Binary Logistic regression analyses were performed for the influence of attitudes and behaviors towards SSBs consumption. The bidirectional ordered classification data were compared by $\chi^{2}$ trend test. The consumption times and risk score were described by Mean \pm SD, and the comparison between groups was performed by ANOVA analysis followed by LSD. All test were 2 sided. $P \leq 0.05$ was considered statistically significant.

\section{Results}

\section{Demographic characteristics of analysis population in survey 2020}

All students submitted the questionnaire and the response rate was $100 \%$. Excluding those invalid and inconsistency between the two inquiries, 1466 students in survey 2020 in total were included in the analysis sample of cross-sectional study. Sociodemographic information of participants, including gender, region, family structure, household monthly income per capita, father's education level, mother's education level and pocket money per month for students, were shown in Table 1. 
The SSBs consumption frequency of students with different SSBs-related unhealthy attitudes or behaviors

Among 1466 respondents, $5.1 \%$ consumed SSBs every day and $13.6 \%$ consumed it 3-6 times/week. 680 (46.4\%) junior school students would consume SSBs just because they want to drink, 121 (8.3\%) would drink SSBs as water, 66 (4.5\%) thought SSBs will not affect health, and $338(23.1 \%)$ would purchase sugary drinks in advance. Students with above unhealthy attitude or behavior had higher SSBs consumption frequency $(P<0.05)$. See Table 2 for details.

Table 1 Sociodemographic characteristics of study subjects in survey $2020(n=1466)$

\begin{tabular}{|c|c|c|c|}
\hline Sociodemographic Variable & & $\mathrm{n}$ & $\%$ \\
\hline \multirow[t]{2}{*}{ Gender } & Male & 758 & 51.7 \\
\hline & Female & 708 & 48.3 \\
\hline \multirow[t]{2}{*}{ Region } & Urban & 631 & 43.0 \\
\hline & Rural & 835 & 57.0 \\
\hline \multirow[t]{2}{*}{ Family structure } & Nuclear & 1080 & 73.7 \\
\hline & Non-nuclear & 386 & 26.3 \\
\hline \multirow[t]{3}{*}{ Household monthly income per capita } & $<¥ 1000$ & 94 & 6.4 \\
\hline & $¥ 1000-5000$ & 982 & 67.0 \\
\hline & $>¥ 5000$ & 390 & 26.6 \\
\hline \multirow[t]{3}{*}{ Father's education level } & Primary school and illiteracy & 77 & 5.3 \\
\hline & Middle school & 1099 & 75.0 \\
\hline & College and above & 290 & 19.8 \\
\hline \multirow[t]{3}{*}{ Mother's education level } & Primary school and illiteracy & 117 & 8.0 \\
\hline & Middle school & 1040 & 70.9 \\
\hline & College and above & 309 & 21.1 \\
\hline \multirow[t]{4}{*}{ Pocket money per month } & None & 296 & 20.2 \\
\hline & $<¥ 100$ & 621 & 42.4 \\
\hline & $¥ 100-200$ & 364 & 24.8 \\
\hline & $>¥ 200$ & 185 & 12.6 \\
\hline
\end{tabular}

Table 2 The SSBs Consumption frequency of junior school students with different beverage-related attitudes and behaviors, $\mathrm{n}(\%)$ 


\begin{tabular}{|c|c|c|c|c|c|c|c|c|}
\hline & $\mathrm{n}$ & $\begin{array}{l}\geq 1 \\
\text { times } \\
\text { /day }\end{array}$ & $\begin{array}{l}3-6 \\
\text { times } \\
\text { /week }\end{array}$ & $\begin{array}{l}\text { 1-2 times } \\
\text { /week }\end{array}$ & $\begin{array}{l}1-3 \text { times } \\
\text { /month }\end{array}$ & $\begin{array}{l}<1 \text { times } \\
\text { /month }\end{array}$ & $Z / \chi^{2}$ & $\begin{array}{l}\boldsymbol{P} \\
\text { value }\end{array}$ \\
\hline \multicolumn{9}{|c|}{ Just want to drink SSBs } \\
\hline Yes & 680 & $26(3.8)$ & $\begin{array}{l}73 \\
(10.7)\end{array}$ & $\begin{array}{l}237 \\
(34.9)\end{array}$ & $\begin{array}{l}250 \\
(36.8)\end{array}$ & $94(13.8)$ & -6.192 & $<0.001$ \\
\hline No & 786 & $10(1.3)$ & $35(4.5)$ & $\begin{array}{l}262 \\
(33.3)\end{array}$ & $\begin{array}{l}277 \\
(35.2 \rrbracket\end{array}$ & $\begin{array}{l}202 \\
(25.7)\end{array}$ & & \\
\hline \multicolumn{9}{|c|}{ Drink SSBs as water } \\
\hline Yes & 121 & $\begin{array}{l}19 \\
(15.7)\end{array}$ & $\begin{array}{l}32 \\
(26.4)\end{array}$ & $40(33.1)$ & $23(19.0)$ & $7(5.8)$ & -9.343 & $<0.001$ \\
\hline No & 1345 & $17(1.3)$ & $76(5.7)$ & $\begin{array}{l}459 \\
(34.1)\end{array}$ & $\begin{array}{l}504 \\
(37.5)\end{array}$ & $\begin{array}{l}289 \\
(21.5)\end{array}$ & & \\
\hline \multicolumn{9}{|c|}{ Deem SSBs not affect health } \\
\hline Yes & 66 & $5(7.6)$ & $\begin{array}{l}17 \\
(25.8)\end{array}$ & $19(28.8)$ & $19(28.8)$ & $6(9.1)$ & 31.653 & $<0.001$ \\
\hline $\begin{array}{l}\text { Not } \\
\text { sure }\end{array}$ & 135 & $10(7.4)$ & $\begin{array}{l}16 \\
(11.9)\end{array}$ & $48(35.6)$ & $392(8.9)$ & $22(16.3)$ & & \\
\hline No & 1265 & $21(1.7)$ & $75(5.9)$ & $\begin{array}{l}432 \\
(34.2)\end{array}$ & $\begin{array}{l}469 \\
(37.1)\end{array}$ & $\begin{array}{l}268 \\
(21.2)\end{array}$ & & \\
\hline \multicolumn{9}{|c|}{ Purchase SSBs in advance } \\
\hline Yes & 338 & $20(2.5)$ & $29(7.4)$ & $\begin{array}{l}113 \\
(34.0)\end{array}$ & $\begin{array}{l}110 \\
(35.9)\end{array}$ & $66(20.2)$ & 23.87 & $<0.001$ \\
\hline No & 1128 & $16(1.4)$ & $79(7.0)$ & $\begin{array}{l}386 \\
(34.2)\end{array}$ & $\begin{array}{l}417 \\
(37.0)\end{array}$ & $\begin{array}{l}230 \\
(20.4)\end{array}$ & & \\
\hline
\end{tabular}

\section{Binary Logistic Regression of the influence of unhealthy attitude or behavior factors on SSBs consumption frequency}

In the multivariate analysis, frequency was taken as the dependent variable, and attitude or behavior factors, sociodemographic characteristic including gender, region, family structure, household monthly income per capita, father's education level, mother's education level and pocket money per month were taken as the independent variable. The code of the variable in model was shown in Table 3. OR means the multiple of the increased risk of high beverage consumption frequency for each grade of increase in independent variables. We fitted six multilevel logistic regression models. The first was the demographic characteristic model (Model 1). The second model included the family characteristic described above in addition to demographic characteristic (Model 2). The following four models included four attitudes or behaviors step by step (Model 3-6). The $\mathrm{R}^{2}$ of the models and odds ratios of variables were reported in Table 4. 
The results showed that the final binary logistic regression was significant $\left(R^{2}=31.1 \%, P=0.001\right)$ (Table 4). Variance in membership group (SSBs consumption frequency $>3$ times/week) explained by each group of variables was: demographic characteristics, $0.2 \%$; family characteristics, additional $8.8 \%$; "Just want to drink SSBs", additional 3.7\%; "Deem SSBs not affect health", additional 6.0\%; "Drink SSBs as water", additional 10.8\%; and "Purchase in advance", additional 1.6\%. The attitude and behavior factors contributed to $22.1 \%$ of the $31.1 \%$ variation that could be explained. In the final model, the four most influential factors were "Drink SSBs as water"(OR=10.288), "Deem SSBs not affect health" (OR=2.735), "Just want to drink SSBs" (OR=2.302) and "Purchase SSBs in advance" (OR=2.245). In addition, gender, household income per capita, father's education level and pocket money per month were also significant in final model $(P<0.05)$.

Table 3 The code of variables in binary logistic regression model 


\begin{tabular}{|c|c|}
\hline Variables & Points \\
\hline Gender & Male $=1$, Female $=2$ \\
\hline Region & Urban=1, Rural=2 \\
\hline Family structure & Nuclear $=1$, Non-nuclear $=2$ \\
\hline \multirow[t]{3}{*}{ Household income per capita } & $<¥ 1000=1$ \\
\hline & $¥ 1000-5000=2$ \\
\hline & $>¥ 5000=3$ \\
\hline \multirow[t]{3}{*}{ Father's education level } & Primary school or illiteracy $=1$ \\
\hline & Middle school=2 \\
\hline & College and above $=3$ \\
\hline \multirow[t]{3}{*}{ Mother's education level } & Primary school or illiteracy $=1$ \\
\hline & Middle school=2 \\
\hline & College and above $=3$ \\
\hline \multirow[t]{4}{*}{ Pocket money per month } & None $=1$ \\
\hline & $<¥ 100=2$ \\
\hline & $¥ 100-200=3$ \\
\hline & $>¥ 200=4$ \\
\hline Just want to drink SSBs & $\mathrm{No}=0, \mathrm{Yes}=1$ \\
\hline Deem SSBs affect health & No $=0$, Not sure $=1$, Yes $=2$ \\
\hline Drink SSBs as water & No $=0$, Yes $=1$ \\
\hline Purchase in advance & No $=0$, Yes $=1$ \\
\hline
\end{tabular}

Table 4 Results of binary logistic regression analysis: risk factors versus SSBs consumption frequency 


\begin{tabular}{|c|c|c|c|c|c|}
\hline \multirow[t]{2}{*}{ Model } & \multicolumn{2}{|c|}{ Nagelkerke's $\mathrm{R}^{2}$} & \multirow[t]{2}{*}{ Variables } & \multirow[t]{2}{*}{ OR:95\% $\mathrm{Cl}^{\mathrm{a}}$} & \multirow{2}{*}{$\begin{array}{l}P \\
\text { value }^{\text {a }}\end{array}$} \\
\hline & Total & Change & & & \\
\hline \multirow[t]{2}{*}{$\begin{array}{l}\text { Model } \\
1\end{array}$} & $\begin{array}{l}0.002 \\
\bigotimes \text { n.s. }\end{array}$ & $\begin{array}{l}0.002 \\
\text { (n.s.) }\end{array}$ & Gender & $0.581(0.388-0.871)$ & 0.009 \\
\hline & & & Region & n.s. & \\
\hline \multirow{5}{*}{$\begin{array}{l}\text { Model } \\
2\end{array}$} & $0.09 *$ & $0.088^{*}$ & Family structure & n.s. & \\
\hline & & & $\begin{array}{l}\text { Household income per } \\
\text { capita }\end{array}$ & $2.227(1.528-3.245)$ & $<0.001$ \\
\hline & & & Father's education level & $0.539(0.327-0.887)$ & 0.015 \\
\hline & & & Mother's education level & n.s. & \\
\hline & & & Pocket money per month & $1.621(1.308-2.011)$ & $<0.001$ \\
\hline $\begin{array}{l}\text { Model } \\
3\end{array}$ & $0.127 *$ & $0.037 *$ & Just want to drink SSBs & $2.302(1.524-3.478)$ & $<0.001$ \\
\hline $\begin{array}{l}\text { Model } \\
4\end{array}$ & $0.187^{*}$ & $0.06^{*}$ & $\begin{array}{l}\text { Deem SSBs not affect } \\
\text { health }\end{array}$ & $2.735(2.032-3.681)$ & $<0.001$ \\
\hline $\begin{array}{l}\text { Model } \\
5\end{array}$ & $0.295^{\star}$ & $0.108 *$ & Drink SSBs as water & $\begin{array}{l}10.288(6.392- \\
16.558)\end{array}$ & $<0.001$ \\
\hline $\begin{array}{l}\text { Model } \\
6\end{array}$ & $0.311^{*}$ & $0.016^{\star}$ & Purchase SSBs in advance & $2.245(1.454-3.465)$ & $<0.001$ \\
\hline
\end{tabular}

n.s.: not significant

a: OR and $P$ value in final model

*: $P<0.005$

The relationship between SSBs consumption frequency and the risk scores for unhealthy attitude and behavior combinations

In order to observe the comprehensive effect of unhealthy attitudes and behaviors to SSBs consumption, we created a risk scores variable (See the methods section for details). As shown in Figure 2, as this risk score increased, the proportion of students with high SSBs consumption frequency (e.g. " $\geq 1$ times/day") increased, while the proportion of that with low frequency (e.g. "<1 times/month") decreased. The consumption frequency of SSBs was positively correlated with the risk score (the $\chi^{2}$-trend value was 127.470, $P<0.001)$. The higher the risk score, the higher the consumption frequency.

Figure 2. Composition of SSBs consumption frequencies among junior school students with different risk scores 
The unhealthy attitude or behavior factors and SSBs consumption in long term trend analysis 2012-2020

Using data from three surveys 2012, 2018 and 2020, we further analyzed the relationship between attitude or behavior factors and frequency of beverage consumption as well as long-term trends. Among junior school students, the consumption frequency decreased with the growth of the year $\left(\chi^{2}\right.$-trend $=144.153, P<0.001)$ under the same gender composition $\left(\chi^{2}=1.096, P=0.578\right)$ (Table 5). The proportion of students who choose "Just want to drink SSBs" was different between 2012, 2018 and $2020\left(\chi^{2}=24.513\right.$, $P<0.001)$, but there was no linear trend $\left(\chi^{2}=0.034, P=0.853\right)$. The proportion of students who "Drink SSBs as water" decreased with the increase of the year $\left(X^{2}\right.$-trend $\left.=154.730, P<0.001\right)$. The proportion of students who "Deem SSBs not affect health" or "not sure" also reduced with the increase of the year $\left(\chi^{2}\right.$. trend $=145.847, P<0.001$ ) (Table 6). We converted the frequency into times of monthly consumption to show the long term trend in the Figure 3. And the long term trend of the risk score combined three unhealthy attitude or behavior factors was also showed in Figure 3. Both SSBs consumption times $(P<0.001)$ and risk score $(P<0.001)$ decreased with the passage of time and there was significant positive correlation between them $(r=0.314, P<0.001)$. (Fig. 3). The detailed description was shown in Table 7.

Table 5 Variation trend of SSBs consumption frequency among junior school students in 2012, 2018 and 2020, n (\%)

\begin{tabular}{|c|c|c|c|c|c|c|c|c|}
\hline & $n$ & $\begin{array}{l}\geq 1 \text { times } \\
\text { /day }\end{array}$ & $\begin{array}{l}\text { 3-6times } \\
\text { /week }\end{array}$ & $\begin{array}{l}\text { 1-2times } \\
\text { /week }\end{array}$ & $\begin{array}{l}\text { 1-3times } \\
\text { /month }\end{array}$ & $\begin{array}{l}<1 \text { times } \\
\text { /month }\end{array}$ & $\chi^{2}$-trend & $\boldsymbol{P}_{\text {-trend }}$ \\
\hline 2012 & 189 & $15(7.9)$ & 64 (33.9) & $80(42.3)$ & $18(9.5)$ & $12(6.3)$ & 144.153 & $<0.001$ \\
\hline 2018 & 1338 & $86(6.4)$ & $\begin{array}{l}193 \\
(14.4)\end{array}$ & $\begin{array}{l}458 \\
(34.2)\end{array}$ & $357(26.7)$ & $\begin{array}{l}244 \\
(18.2)\end{array}$ & & \\
\hline 2020 & 1200 & $24(2.0)$ & $\begin{array}{l}129 \\
(10.8)\end{array}$ & $\begin{array}{l}429 \\
(35.8)\end{array}$ & $\begin{array}{l}388 \\
(32.3)\end{array}$ & $\begin{array}{l}230 \\
(19.2)\end{array}$ & & \\
\hline
\end{tabular}

Table 6 Variation trend of three unhealthy attitudes and behaviors in 2012, 2018 and 2020, n (\%) 


\begin{tabular}{|lllllll|}
\hline & & 2012 & 2018 & 2020 & $\chi^{2}$ & $\begin{array}{l}P \\
\text { value }\end{array}$ \\
\hline Just want to drink SSBs & Yes & $\begin{array}{l}111 \\
(58.7)\end{array}$ & $548(41.0)$ & $560(46.7)$ & 24.51 & 0.003 \\
\hline & No & $78(41.3)$ & $790(59.0)$ & $640(53.3)$ & & \\
\hline Drink SSBs as water & Yes & $81(42.9)$ & $269(20.1)$ & $101(8.4)$ & 164.52 & $<0.001$ \\
\hline & No & $\begin{array}{l}108 \\
(57.1)\end{array}$ & $\begin{array}{l}1069 \\
(79.9)\end{array}$ & $\begin{array}{l}1099 \\
(92.6)\end{array}$ & & \\
\hline $\begin{array}{l}\text { Deem SSBs not affect } \\
\text { health }\end{array}$ & No & $30(15.9)$ & $77(5.8)$ & $51(4.2)$ & 409.98 & $<0.001$ \\
\hline & Not & $115(60.8)$ & $164(12.3)$ & $126(10.5)$ & & \\
\hline & Sure & & & & & \\
\hline & Yes & $44(23.3)$ & $\begin{array}{l}1097 \\
(82.0)\end{array}$ & $\begin{array}{l}1023 \\
(85.2)\end{array}$ & & \\
\hline
\end{tabular}

Table 7 Variation trend of consumption times per month and risk scores in 2012, 2018 and 2020, Mean \pm SD

\begin{tabular}{|llllll|}
\hline & 2012 & 2018 & 2020 & $F$ & $P$ value \\
\hline Consumption times per month & $11.2 \pm 8.4$ & $7.0 \pm 7.9^{*}$ & $4.7 \pm 5.5^{\star \#}$ & 85.163 & $<0.001$ \\
\hline Risk scores & $1.9 \pm 1.0$ & $0.8 \pm 0.9^{*}$ & $0.7 \pm 0.8^{* \#}$ & 179.335 & $<0.001$ \\
\hline
\end{tabular}

*: compared with 2012, $P<0.05$

\#\compared with 2018, $P<0.05$

\section{Discussion}

With the continuous development of economy and beverage industry, more and more students consume sugary beverages habitually, and seem to be more difficult to resist it than adults are. Habitual consumption of sugary beverages was not only determined as one of the fastest growing behavioral factors contributing to burden of disease in 1990-2016 [3], but also was linked to chronic diseases in children. A quantitative meta-analysis in New Zealand based on cohort studies found that the risk of being overweight or obese among children who consumed one serving of sugary beverages per day increased by $55 \%$ compared with those with the lowest intake [15]. High beverage consumption was also associated with elevated blood pressure in children aged 11 12 in Netherlands [16]and students in Iran [17]. Two surveys in China involving thousands of people respectively demonstrated that high SSBS intake was positively associated with an increased risk of metabolic syndrome [18] and serum total 
cholesterol and low-density lipoprotein-cholesterol (LDL-C) [19]. Therefore, we should pay more attention to the consumption behavior of sugary drinks in children and adolescents.

In recent years, a variety of active measures successively taken by some countries to intervene this preventable factor, such as proclaiming sales ban [24], increasing taxes [25-27], restricting sales prices[28] and implementing health warning policies[29, 30], had achieved good results. However, studies found that added tax on SSBs would also increase in volume of sales in surrounding untaxed areas [27], and the reduction of SSBs intake by sales ban would be better in the longer term if combined with targeted motivational education interventions [24]. Therefore, it is urgent to understand the most important factors to SSBs consumption among junior school students, which would dramatically contribute to reduce their beverage intake radically.

In our study, after controlling for general and family variables, "Just want to drink SSBs ", "Deem SSBs not affect health ", "Drink SSBs as water " and "Purchase SSBs in advance" were all independent factors that influence frequency of SSBs consumption among junior school students. Moreover, the contribution of above factors was far higher than that of sociodemographic factors, accounting for two-thirds of all the explicable reasons. Above results were further validated in the stratified analysis by region or gender (see details in Supplementary Table 1 and Table 2). Although the contribution of attitudes and behaviors were dissimilarity in different region or gender, and certain factors among them didn't enter into the final model, such as "Purchase SSBs in advance " not in southern stratified model and "Just want to drink SSBs " not in northern stratified model, the attitudes and behaviors as a whole were major factors influencing the consumption of sugary drinks. The same change trend and good correlation between SSBs consumption frequency and unhealthy attitudes or behaviors from 2012-2020 also further proved the relationship between attitude or behavior factors and consumption frequency of sugary drinks. Wanting is the motivation of consuming SSBs [31]. The degree of cognition of the health effects of beverages directly affects the frequency of drinking SSBs. Many investigations had confirmed that home availability of sugar-sweetened beverages was positively associated with their consumption [32]. SSBs are a source of water with high sugar and low nutrients, and drinking SSBs as water can lead to an excessive intake of sugar. Therefore, reducing sugary drinks and increasing water intake were crucial goal and often used for effectiveness evaluation of sugar-sweetened beverage interventions [33].

In conclusion, these four attitude or behavior factors are extraordinarily important factors that affect the consumption frequency of SSBs among junior school students in China. Childhood and adolescence is a critical period to develop good habits, and correct cognitive contributes to the formation of healthy eating behavior, and their lifelong maintenance. Therefore, education aimed to change students' cognition targeted above risk factors, not general education or knowledge, would more contribute to the reduction of SSBs consumption $[20,21]$.

Unhealthy attitudes and behaviors for SSBs consumption were sign of low health literacy. A study in the rural Lower Mississippi Delta reported that the higher the health literacy, the lower the SSBs consumption, and every additional 1 point on the health literacy scores was associated with 34 kilocalories/d lower 
SSBs intakes [34]. We set up a SSBs consumption risk score through combining three attitude or behavior factors, and found that the consumption frequency increased with the increase of the risk score in survey 2020. The same trend was also obtained from the 2018 survey $\left(X^{2}\right.$-trend $\left.=82.169 \otimes P<0.001\right)$ (

Supplementary Figure 1). In order to compare with the survey 2012 and 2018, three not four factors were combined to create risk score variable. However, the risk score combined with four factors has also been shown to be significantly correlated with the frequency of consumption among junior school students $\left(\chi^{2}\right.$. trend $=127.470 \otimes P<0.001$ ) (The results were not shown). Besides, the risk score was positively correlated with the consumption times of SSBs from 2012 to 2020. This finding indicated that the risk score may be used as a predictive indicator to the SSBs consumption frequency, or a screening tool to find students with high SSBs consumption risk. Targeted efforts should be used in reducing consumption of SSBs among students with high risk scores.

NHANES reported that almost two-thirds of boys and girls consumed at least one sugar-sweetened beverage on a given day in 2011-2014 [9]. In China, a survey of urban children and adolescents aged 3 to 18 in 9 provinces and cities showed that the consumption rate of carbonated beverages was $45.1 \%$ [35]. Our research showed that the proportion of students who drink 1-3 times a week was the largest, while the proportion of those who drank more than 3 times a week or everyday were basically the same as the results of the previous study.

After the adverse health effects of added sugars were recognized, sugar or SSBs control also has been listed into various national and global dietary guidelines and recommendations successively. For example, World Health Organization advised in 2015 that the energy provided by free sugars should be reduced to $<10 \%$, and the intake with a $<5 \%$ energy ratio would have additional benefits in reducing the risk of noncommunicable diseases (specifically excess weight gain and dental caries) in children [36]. China also clearly stated in the "Dietary Guidelines for Chinese Residents (2016)" not to drink or to drink less sugary beverages [37]. After that, countries around the world intervened in various forms, and the decreasing trends in SSBs consumption in children and adolescents bubbled up in succession too [7, 3841]. For instance, researcher reported that national SSBs health warning policy not only lessened average SSBs and energy intake about by 20 30 calories per day, but also reduced BMI and obesity prevalence [30]. According data from NHANES, self-reported consumption of SSBs in American children dropped year-by-year from 1999 through 2014 [38]. In our research, we observed the similar decreasing time trends for SSBs intake as well. More importantly, the same decreasing time trends of unhealthy attitudes and behaviors was showed likewise, and the relationship between unhealthy attitude or behavior factors and sugary beverage consumption also gained further support. Among three attitude or behavior factors, "Just want to drink SSBs" reflected students' innate addiction to sweets to some extent, so its change over three surveys was less obvious than another two factors.

In addition to above attitude and behavior factors, gender, household income per capita, father's education level and pocket money per month were also found to be significant to SSBs consumption in our research. These results were supported by other similar studies. The data from school-based National Youth Physical Activity and Nutrition Study showed that male students drank SSBs more likely than 
female students did in US middle school [42]. Fontes, A. S. etc also found women drank SSBs less frequently [11]. Han E reported that children having parents with low education level were more likely to consume sugary drinks than children having parents with high education level in the U.S. [40]. Studies from Norway and Korea had demonstrated that more pocket money for adolescents was strongly related to their high sugary drink consumption $[43,44]$. While students' pocket money is often positively correlated with family income.

In summary, we found in our study that above four unhealthy attitudes or behaviors had great contribution to SSBs consumption frequency among Chinese junior school students. There were some limits yet in this research. First, we used self-reported habitual SSBs consumption frequency. Although the frequency was not exactly equivalent to the quantity and a recall bias for self-reports also existed, it was a direct reflection of consumption custom among students. While unhealthy eating habits has been proven associated with high SSBs consumption [45]. Second, the sample was not nationwide, although we also sampled from the north and south. The results of this study need to be verified in larger and broader populations.

\section{Abbreviations}

SSBs: sugar-sweetened beverages; Cl: Confidence Interval; NHANES: National Health and Nutrition Examination Survey

\section{Declarations}

\section{Acknowledgements}

We thank the junior school students and their parents participated in this research, teachers in the charge of this work in surveyed schools and other students in Nanjing Medical University participated in this work.

\section{Authors' contributions}

JSW conceived the study, designed the questionnaire, drafted the manuscript and had full access to all the data; YTP and DYW were in charge of the design of questionnaire, field survey and analysis of data; RZ and RJA were involved in the administration of the project and analysis of the data; XFL participated in data analysis and draft revision. All authors read and revised this manuscript and approved the final version. JSW takes responsibility for the final manuscript content.

\section{Funding}

This study was supported by grants from the National Natural Science Foundation of China (No. 81602879), the Priority Academic Program Development of Jiangsu Higher Education Institutions (PAPD) (Public Health and Preventive Medicine) and the Innovation and Entrepreneurship Training Program for 
college students in Jiangsu Province (No.201410312052X). The funders had no role in study design, data collection and analysis, decision to publish, or preparation of the manuscript.

\section{Availability of data and materials}

The data in this research from junior school students was prohibited for publicly available due to the ethical restrictions. The datasets used and/or analyzed during the current study are however available from the corresponding author upon reasonable request and after permission of the Ethics Committee of Nanjing Medical University on a case-by-case basis.

\section{Ethics approval and consent to participate}

All junior students and their parents gave informed consent to participate in this study. Ethical approval was granted by the Ethics Committee of Nanjing Medical University in Nanjing, Jiangsu, China, 21/12/2017, No.392.

\section{Consent for publication}

Not applicable

\section{Competing interests}

All authors have disclosed any actual or potential competing interests regarding the submitted article and the nature of those interests, and declare no conflict of interest. The funders had no role in study design, data collection and analysis, decision to publish, or preparation of the manuscript, and also had no conflicts of interest.

\section{Author details}

1. 2016 grade, School of Public Health, Nanjing Medical University, Nanjing 211166, China.

2. Department of Maternal, Child and Adolescent Health, School of Public Health, Nanjing Medical University, Nanjing 211166, China.

3. 2017 grade, School of Pediatrics, Nanjing Medical University, Nanjing 211166, China.

\section{References}

1. China beverage industry association: Sustainable Development Report of China Beverage Industry 2018. Beijing: China beverage industry association. 2018.

2. China beverage industry association: Sustainable Development Report of China Beverage Industry 2014. Beijing: China beverage industry association. 2015.

3. Collaborators GBDRF. Global, regional, and national comparative risk assessment of 84 behavioural, environmental and occupational, and metabolic risks or clusters of risks, 1990-2016: a systematic analysis for the Global Burden of Disease Study 2016. Lancet. 2017;390(10100):1345-422. 
4. Micha R, Penalvo JL, Cudhea F, Imamura F, Rehm CD, Mozaffarian D. Association Between Dietary Factors and Mortality From Heart Disease, Stroke, and Type 2 Diabetes in the United States. JAMA. 2017;317(9):912-24.

5. Singh GM, Micha R, Khatibzadeh S, et al. Estimated Global, Regional, and National Disease Burdens Related to Sugar-Sweetened Beverage Consumption in 2010. Circulation. 2015;132(8):639-66.

6. Malik VS, Li Y, Pan A, et al. Long-Term Consumption of Sugar-Sweetened and Artificially Sweetened Beverages and Risk of Mortality in US Adults. Circulation. 2019;139(18):2113-25.

7. Kit BK, Fakhouri TH, Park S, Nielsen SJ, Ogden CL. Trends in sugar-sweetened beverage consumption among youth and adults in the United States: 1999-2010. Am J Clin Nutr. 2013;98(1):180-8.

8. Rosinger A, Herrick K, Gahche J, Park S. Sugar-sweetened Beverage Consumption Among U.S. Adults, 2011-2014. NCHS Data Brief. 2017(270):1-8.

9. Rosinger A, Herrick K, Gahche J, Park S. Sugar-sweetened Beverage Consumption Among U.S. Youth, 2011-2014. NCHS Data Brief. 2017(271):1-8.

10. Johnson RK, Appel LJ, Brands M, et al. Dietary sugars intake and cardiovascular health: a scientific statement from the American Heart Association. Circulation. 2009;120(11):1011-20.

11. Fontes AS, Pallottini AC, Vieira D, et al. Demographic, socioeconomic and lifestyle factors associated with sugar-sweetened beverage intake: a population-based study. Rev Bras Epidemiol. 2020;23:e200003.

12. Li D, Yu D, Zhao L. Institute for Nutrition and Food Safety, Chinese Center for Disease Control and Prevention:Trend of sugar-sweetened beverage consumption and intake of added sugar in China nine provinces among adults. Journal of Hygiene Research, 2014;43(1).

13. Ma G. Report on Consumption of Sugary Drinks for Children in China. Beijing: China Population Publishing House; 2018.

14. Wang M, Qin M, Xia B. The association of Enamelin, Lactoferrin, and Tumour necrosis factor alpha gene polymorphisms with high caries susceptibility in Chinese children under 4 years old. Arch Oral Biol. 2017;80:75-81.

15. Te Morenga L, Mallard S, Mann J. Dietary sugars and body weight: systematic review and metaanalyses of randomised controlled trials and cohort studies. BMJ. 2012;346:e7492.

16. de Boer EC, de Rooij SR, Olthof MR, Vrijkotte TGM. Sugar-sweetened beverages intake is associated with blood pressure and sympathetic nervous system activation in children. Clin Nutr ESPEN. 2018;28:232-5.

17. Mansouri M, Sharifi F, Yaghubi H, et al. Sugar-sweetened beverages consumption in relation to hypertension among Iranian university students: the MEPHASOUS study. Eat Weight Disord. 2019.

18. Li S, Cao M, Yang C, Zheng H, Zhu Y. Association of sugar-sweetened beverage intake with risk of metabolic syndrome among children and adolescents in urban China. Public Health Nutr. 2020:1-11.

19. Zhu Z, He Y, Wang Z, et al. The associations between sugar-sweetened beverage intake and cardiometabolic risks in Chinese children and adolescents. Pediatr Obes. 2020:e12634. 
20. Nelson MC, Lytle LA, Pasch KE. Improving literacy about energy-related issues: the need for a better understanding of the concepts behind energy intake and expenditure among adolescents and their parents. J Am Diet Assoc. 2009;109(2):281-7.

21. Neuhofer Z, McFadden BR, Rihn A, Wei X, Khachatryan H, House L. Can the updated nutrition facts label decrease sugar-sweetened beverage consumption? Econ Hum Biol. 2020;37:100867.

22. Glasman LR, Albarracin D. Forming attitudes that predict future behavior: a meta-analysis of the attitude-behavior relation. Psychol Bull. 2006;132(5):778-822.

23. Fabrigar LR, Petty RE, Smith SM, Crites SL, Jr. Understanding knowledge effects on attitude-behavior consistency: the role of relevance, complexity, and amount of knowledge. J Pers Soc Psychol. 2006;90(4):556-77.

24. Epel ES, Hartman A, Jacobs LM, et al. Association of a Workplace Sales Ban on Sugar-Sweetened Beverages With Employee Consumption of Sugar-Sweetened Beverages and Health. JAMA Intern Med. 2019:1-8.

25. Silver LD, Ng SW, Ryan-lbarra S, et al. Changes in prices, sales, consumer spending, and beverage consumption one year after a tax on sugar-sweetened beverages in Berkeley, California, US: A beforeand-after study. PLoS Med. 2017;14(4):e1002283.

26. Torres-Alvarez R, Barran-Zubaran R, Canto-Osorio F, et al. Body weight impact of the sugar-sweetened beverages tax in Mexican children: A modeling study. Pediatr Obes. 2020:e12636.

27. Roberto CA, Lawman HG, LeVasseur MT, et al. Association of a Beverage Tax on Sugar-Sweetened and Artificially Sweetened Beverages With Changes in Beverage Prices and Sales at Chain Retailers in a Large Urban Setting. JAMA. 2019;321(18):1799-810.

28. Huse O, Ananthapavan J, Sacks G, et al. The potential cost-effectiveness of mandatory restrictions on price promotions for sugar-sweetened beverages in Australia. Int J Obes (Lond). 2019.

29. Grummon AH, Brewer NT. Health Warnings and Beverage Purchase Behavior: Mediators of Impact. Ann Behav Med. 2020.

30. Grummon AH, Smith NR, Golden SD, Frerichs L, Taillie LS, Brewer NT. Health Warnings on SugarSweetened Beverages: Simulation of Impacts on Diet and Obesity Among U.S. Adults. Am J Prev Med. 2019;57(6):765-74.

31. Rueger SY, Hu H, McNamara P, Cao D, Hao W, King AC. Differences in subjective response to alcohol in heavy- and light-drinking Chinese men versus Caucasian American men. Addiction. 2015;110(1):91-9.

32. Yuhas M, Porter KJ, Hedrick V, Zoellner JM. Using a Socioecological Approach to Identify Factors Associated with Adolescent Sugar-Sweetened Beverage Intake. J Acad Nutr Diet. 2020;120(9):155767.

33. Wang ML, Otis M, Rosal MC, Griecci CF, Lemon SC. Reducing sugary drink intake through youth empowerment: results from a pilot-site randomized study. Int J Behav Nutr Phys Act. 2019;16(1):58.

34. Zoellner J, You W, Connell C, et al. Health literacy is associated with healthy eating index scores and sugar-sweetened beverage intake: findings from the rural Lower Mississippi Delta. J Am Diet Assoc. 
2011;111(7):1012-20.

35. Liu S, Tao W, Mao W, Liu A, Liu Z, Zhang B. Analysis on status of carbonated beverage consumption among children and adolescents aged $3-18$ years in nine provinces of China. Chinese Journal of Health Education. 2015;31(09):819-822+826.

36. Organization WH. Guidelines: sugars intake for adults and children: WHO guidelines approved by the Guidelines Review Committee. http://www.ncbi.nlm.nih.gov/pubmed/25905159. Accessed October 15, 2015. 2015.

37. Chinese Nutrition Society. Dietary Guidelines for Chinese Residents (2016). Beijing: People's Medical Publishing House. 2016.

38. Johnson RK, Lichtenstein AH, Anderson CAM, et al. Low-Calorie Sweetened Beverages and Cardiometabolic Health: A Science Advisory From the American Heart Association. Circulation. 2018;138(9):e126-e40.

39. Gu X TK. Dietary intakes of the US child and adolescent population and their adherence to the current dietary guidelines: trends from 1999 to 2012. FASEB J. 2017;31(suppl):29.1.

40. Han E, Powell LM. Consumption patterns of sugar-sweetened beverages in the United States. J Acad Nutr Diet. 2013;113(1):43-53.

41. Miller G, Merlo C, Demissie Z, Sliwa S, Park S. Trends in Beverage Consumption Among High School Students - United States, 2007-2015. MMWR Morb Mortal Wkly Rep. 2017;66(4):112-6.

42. Centers for Disease $C$, Prevention. Beverage consumption among high school students - United States, 2010. MMWR Morb Mortal Wkly Rep. 2011;60(23):778-80.

43. Sim E, Sohn W, Choi ES, Noh H. Sugar-sweetened beverage consumption frequency in Korean adolescents: based on the 2015 Youth Risk Behavior Web-Based Survey. Int Dent J. 2019;69(5):37682.

44. Jensen JD, Bere E, De Bourdeaudhuij I, et al. Micro-level economic factors and incentives in Children's energy balance related behaviours - findings from the ENERGY European cross-section questionnaire survey. Int J Behav Nutr Phys Act. 2012;9:136.

45. Sharkey JR, Johnson CM, Dean WR. Less-healthy eating behaviors have a greater association with a high level of sugar-sweetened beverage consumption among rural adults than among urban adults. Food Nutr Res. 2011;55.

\section{Figures}




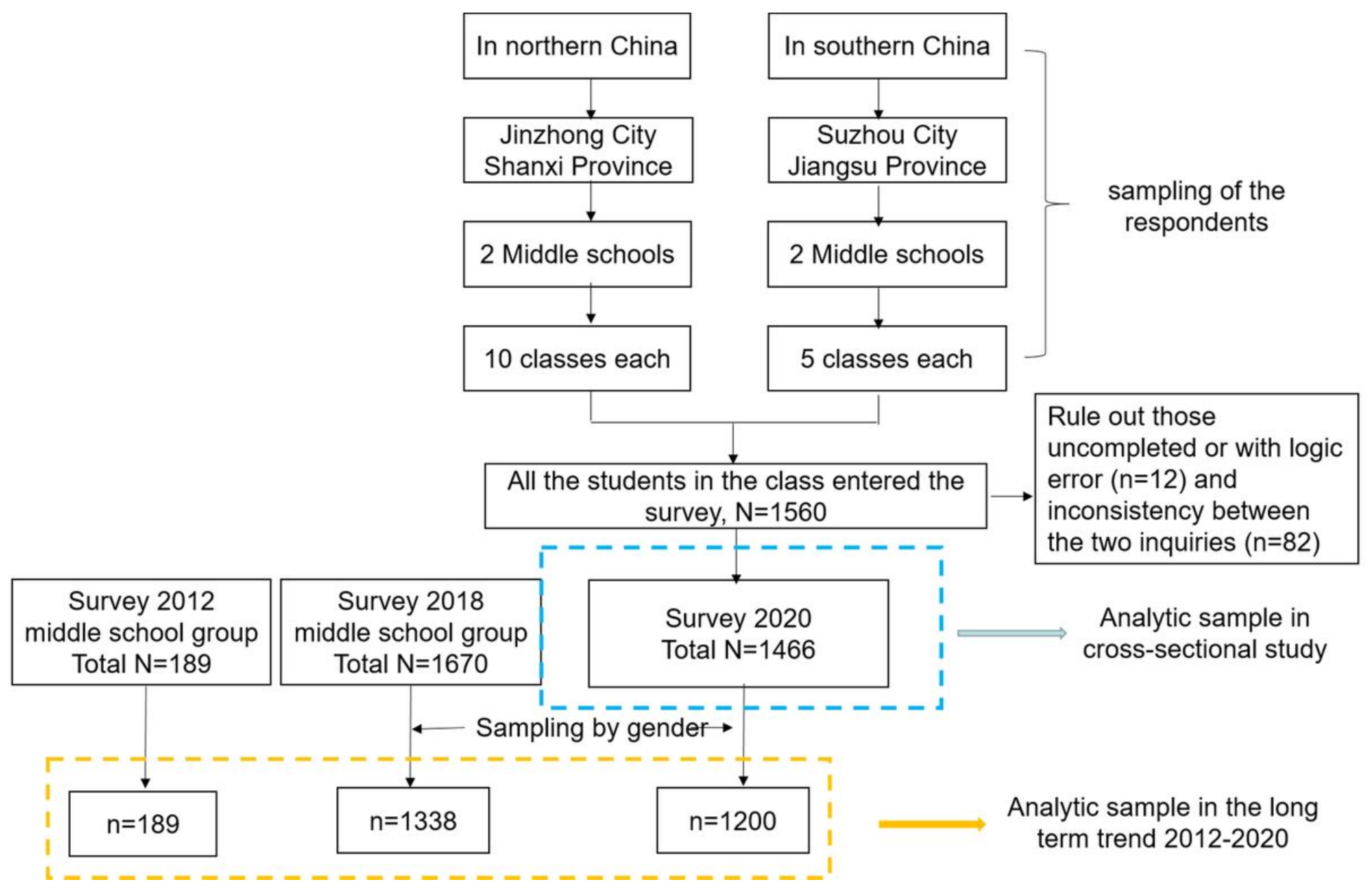

Figure 1

Flow chart for the inclusion of analytic participants in this study 


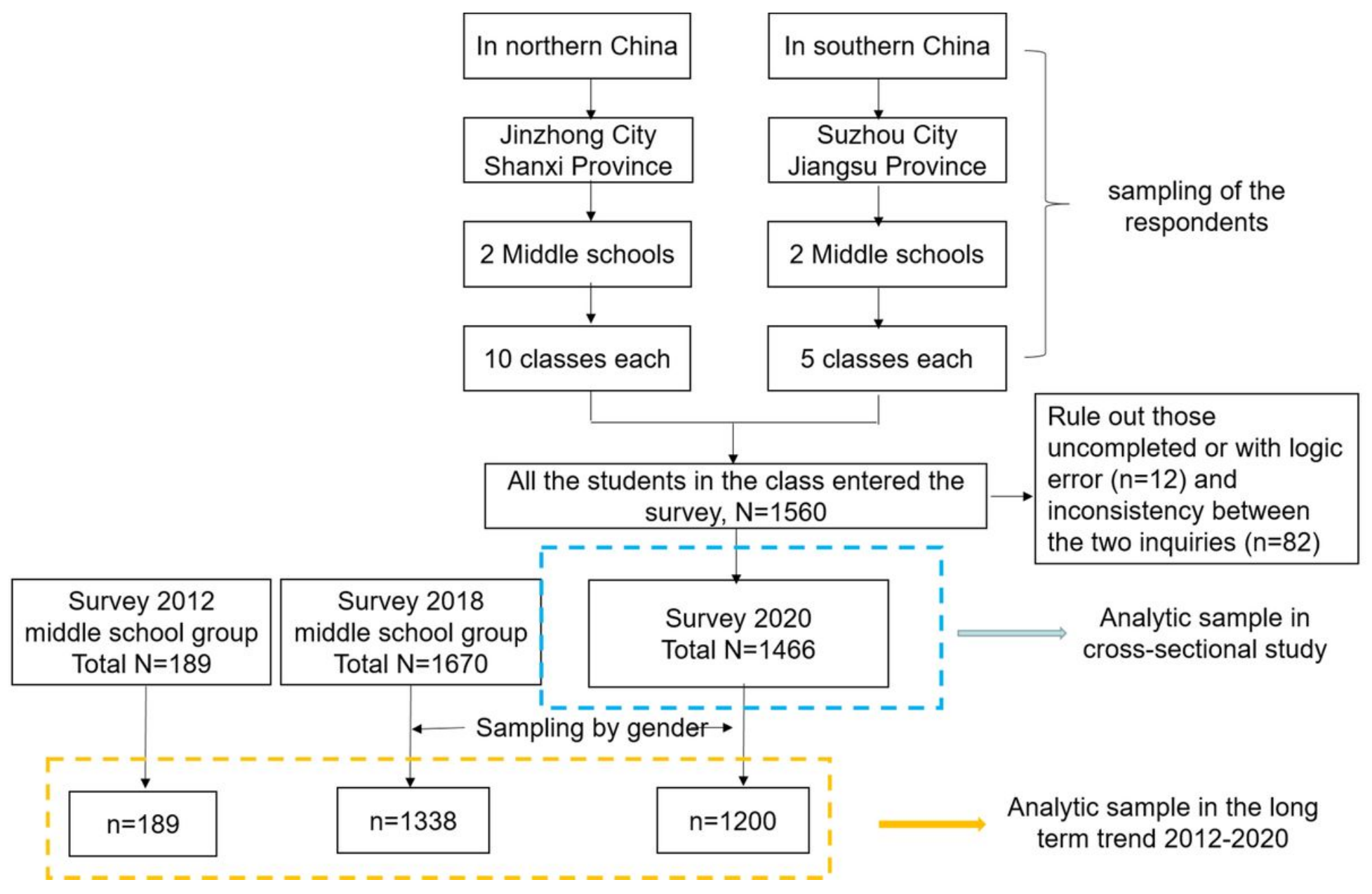

Figure 1

Flow chart for the inclusion of analytic participants in this study 


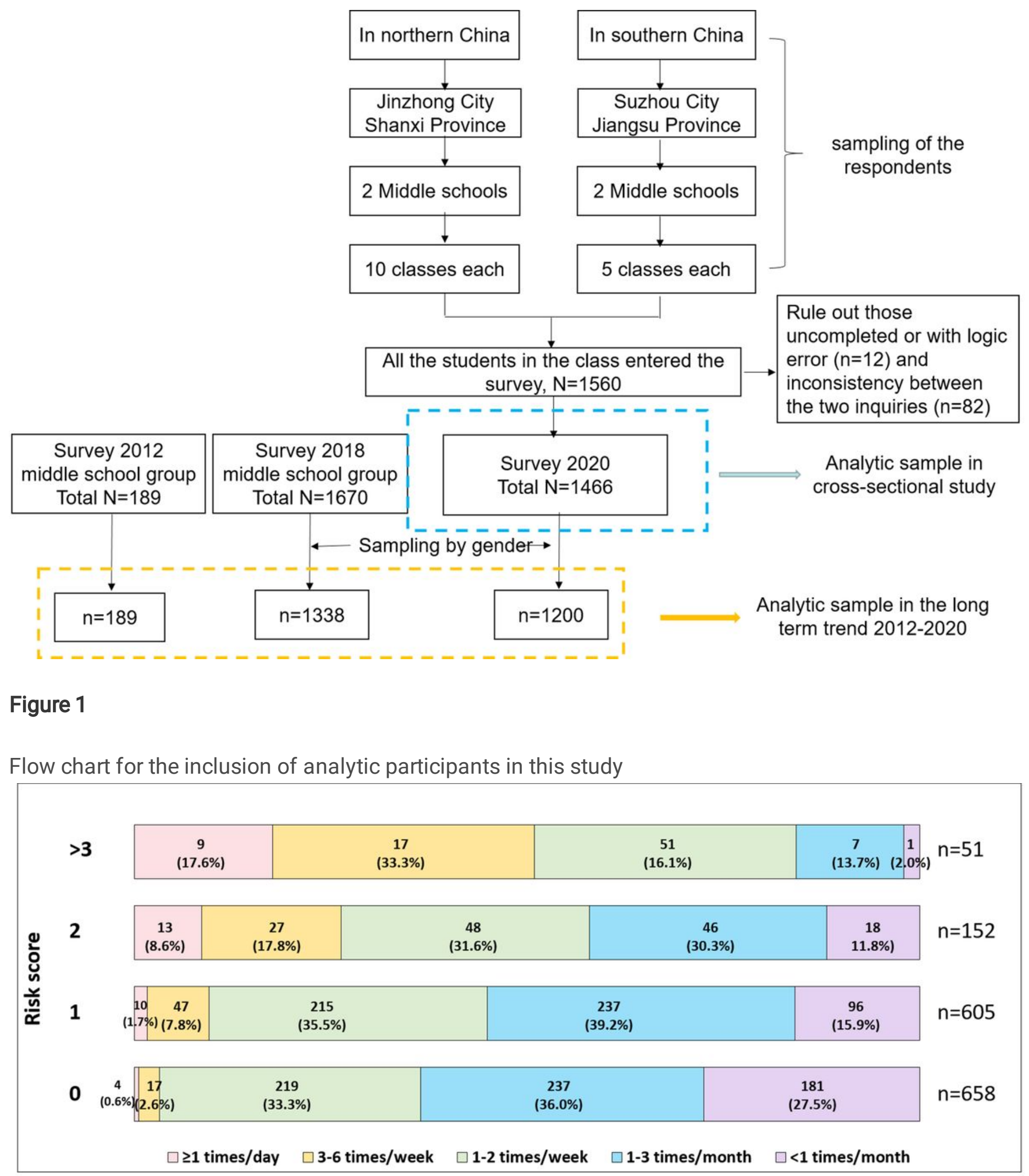

Figure 2

Composition of SSBs consumption frequencies among junior school students with different risk scores 


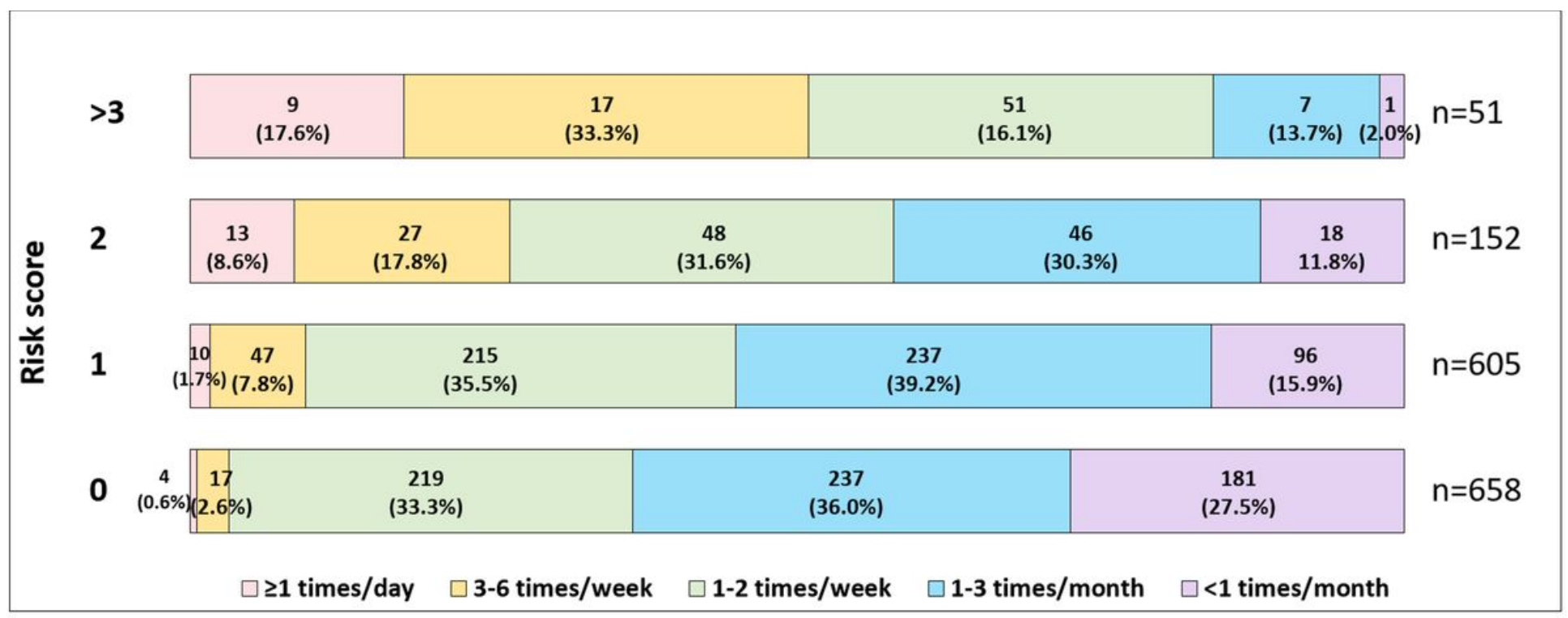

Figure 2

Composition of SSBs consumption frequencies among junior school students with different risk scores

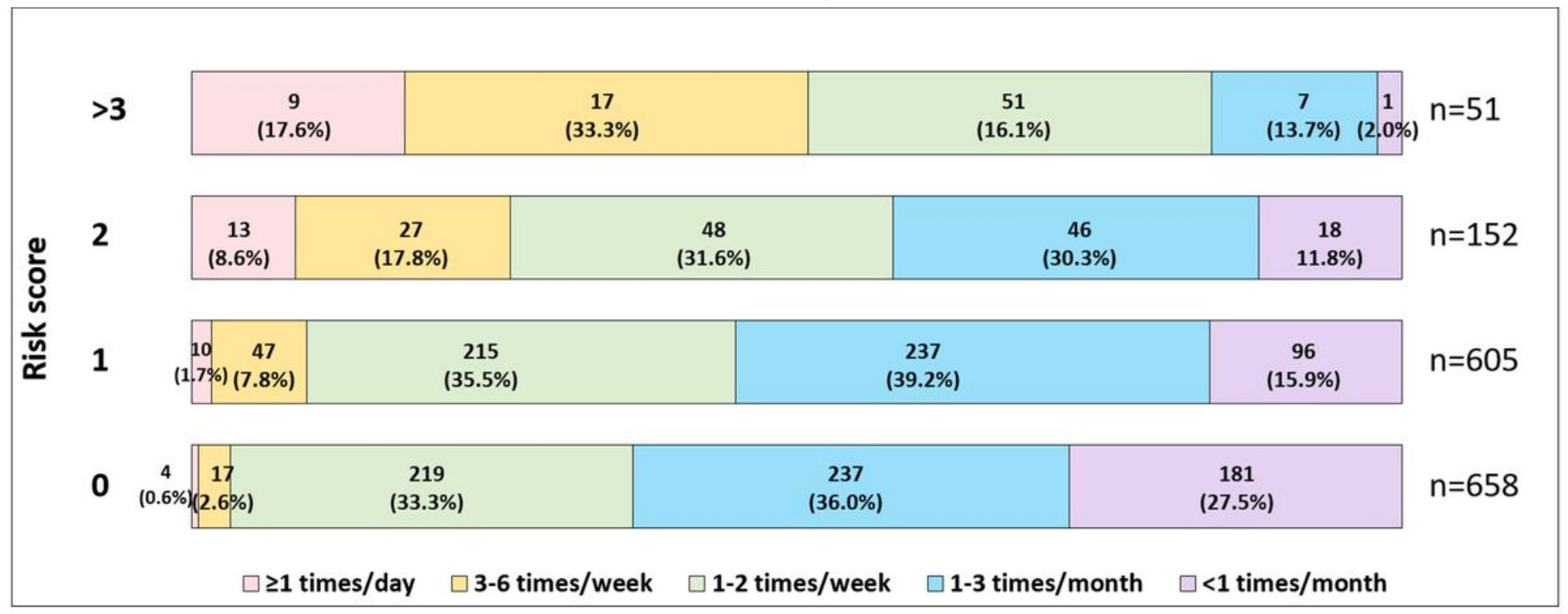

\section{Figure 2}

Composition of SSBs consumption frequencies among junior school students with different risk scores 


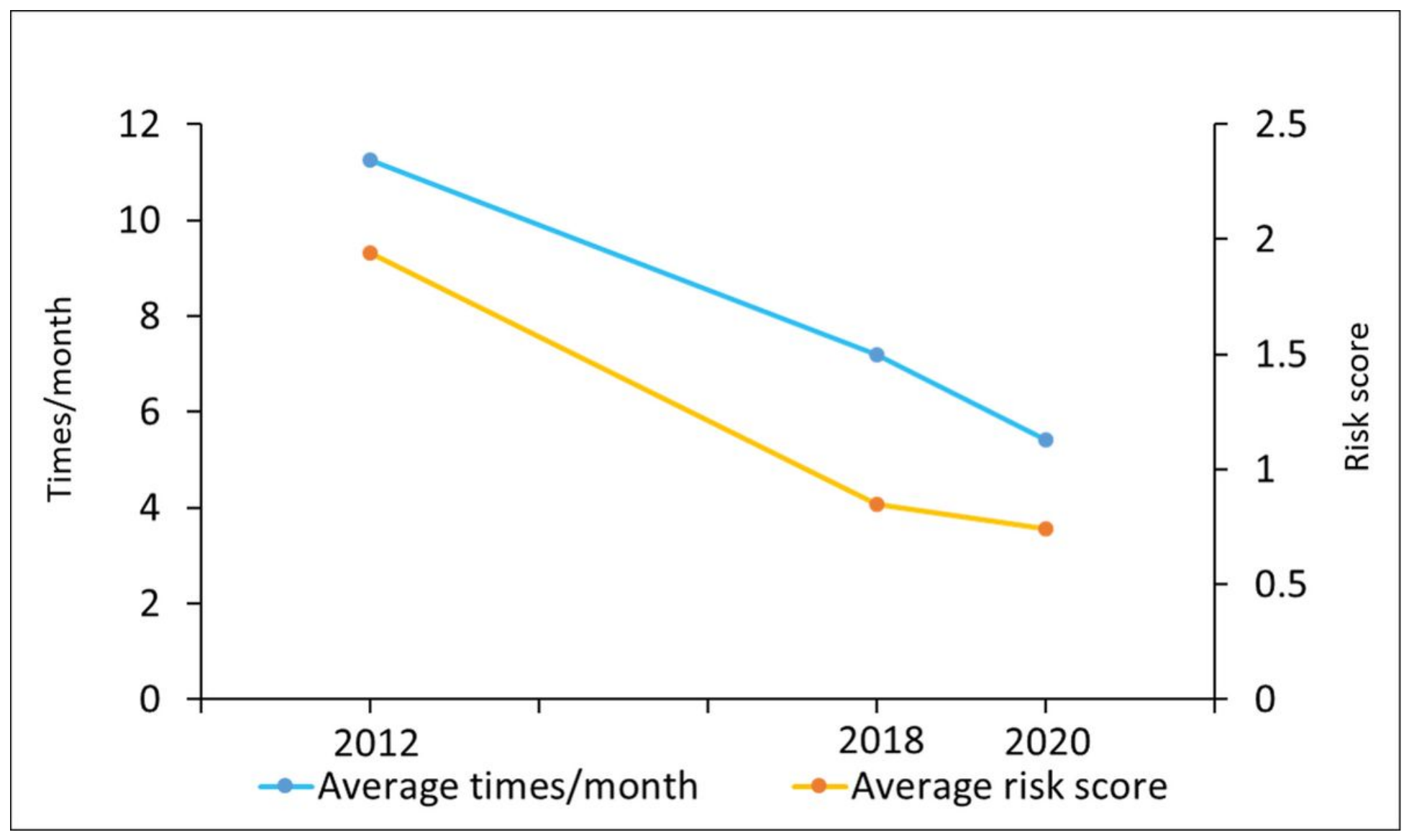

Figure 3

Variation trend of SSBs consumption times and risk score 2012-2020 


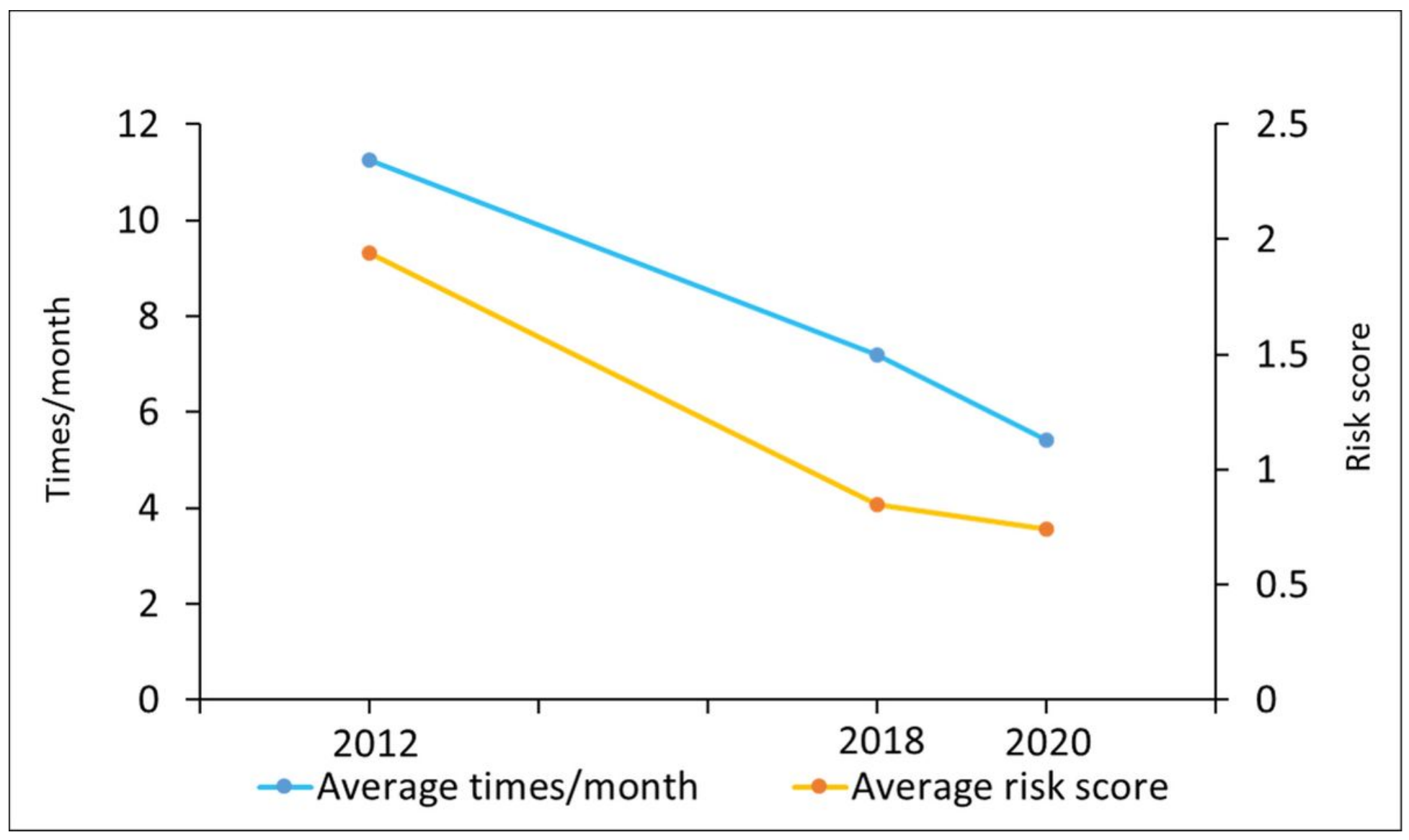

Figure 3

Variation trend of SSBs consumption times and risk score 2012-2020 


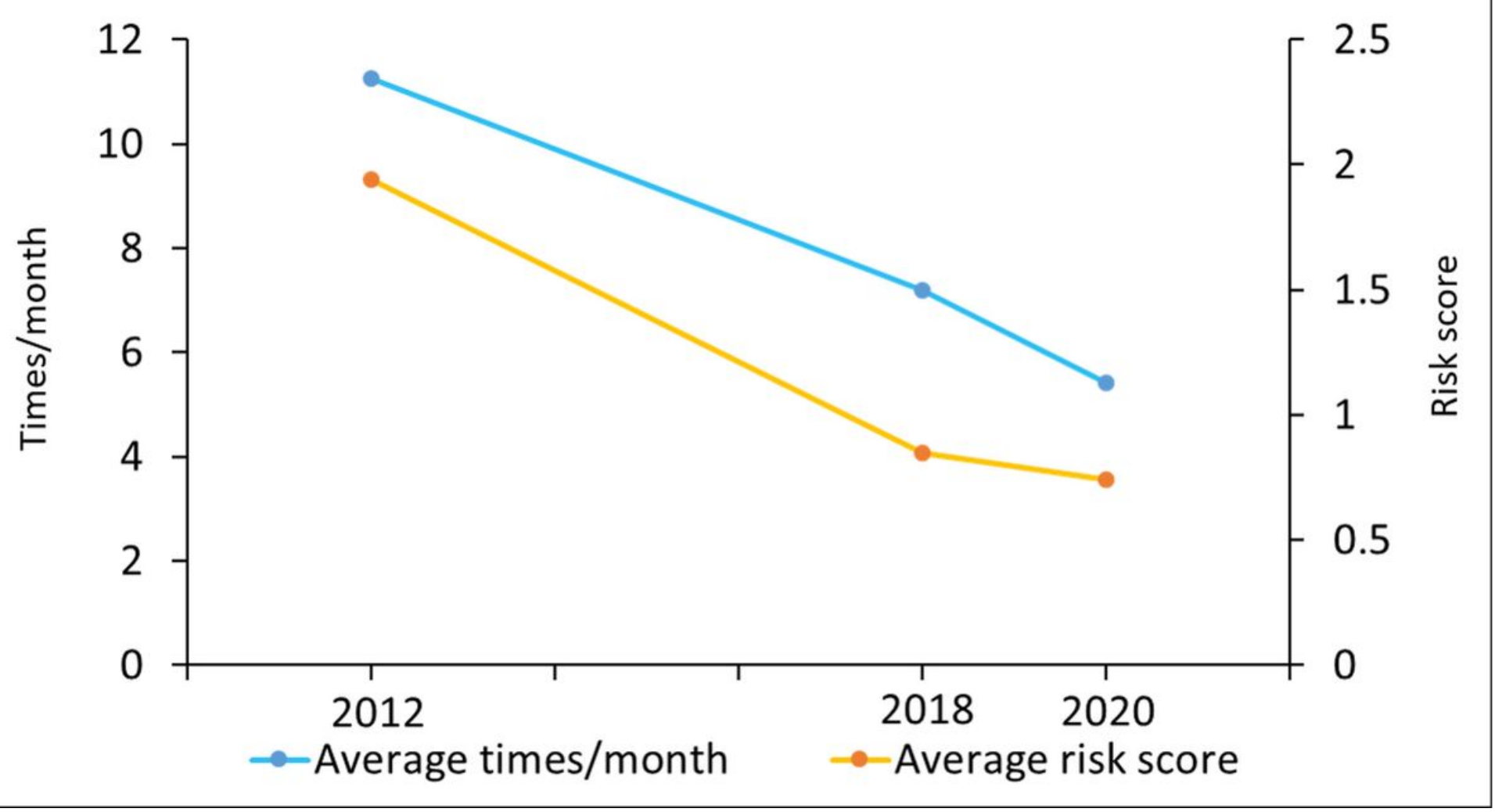

Figure 3

Variation trend of SSBs consumption times and risk score 2012-2020

\section{Supplementary Files}

This is a list of supplementary files associated with this preprint. Click to download.

- SupplementaryFigure1Frequenciesandriskscoresin2018.tif

- SupplementaryFigure1Frequenciesandriskscoresin2018.tif

- SupplementaryFigure1Frequenciesandriskscoresin2018.tif

- SupplementaryTable2Regressionstratifiedbygender.docx

- SupplementaryTable2Regressionstratifiedbygender.docx

- SupplementaryTable2Regressionstratifiedbygender.docx

- SupplementaryTable1Regressionstratifiedbyregion.docx

- SupplementaryTable1Regressionstratifiedbyregion.docx

- SupplementaryTable1Regressionstratifiedbyregion.docx 